\title{
UV-Induced Changes in the Immune Response to Microbial Infections in Human Subjects and Animal Models
}

\author{
Mary Norval ', Johan Garssen ${ }^{2}$, Henk Van Loveren ${ }^{2}$, and Ali A. El-Ghorr ${ }^{1}$
}

\begin{abstract}
Exposure to UV is a recognised risk factor for skin cancer and it also induces immunosuppression to a variety of antigens encountered following the irradiation. The latter property has been demonstrated in rodent models of infections with the microbial agents including viruses, bacteria, protozoa and helminths. In the majority of cases the severity of the symptoms and the microbial load in the host are increased as a result of the immunomodulation. UV can also affect the pathogenesis of some natural microbial infections of human subjects, such as causing recrudescence of herpes simplex virus and contributing to the oncogenic potential of papillomaviruses. Sufficient data have been generated from the animal models to construct a risk assessment in humans for suppression of microbial immune responses induced by sunlight exposure. This estimation requires verification from epidemiological studies and from further work to assay modulation in human immunity to particular pathogens experienced before and after the UV radiation. J Epidemiol, $1999 ; 9$ : S84-S92
\end{abstract}

immunosuppression, microbial infections, UV radiation, herpes simplex virus, human papillomavirus

The consequences of UV radiation for the induction of skin cancer are well recognised, but effects on the pathogenesis of infectious diseases are less well documented. As UV exposure results in not only genotoxic changes but also suppression of cell-mediated immune responses, it is possible that the balance between the host and the invading microorganism could be altered leading to more severe symptoms, reactivation from latency, or increased susceptibility to re-infection. The immunomodulation was first recognised two decades ago in a study of the induction of skin tumours in mice by chronic UVB (280-315 nm) exposure when a decrease in immune surveillance against the tumour cells was observed ${ }^{1}$. Since then UV, particularly UV-B, irradiation has been demonstrated to downregulate systemic as well as local immunity to a variety of antigens. The reason for this may be to prevent excessive inflammation in sun-exposed skin but, if it occurs at the same time as infection or oncogenesis, then it may be disadvantageous to the host.

The main components of the skin immune system have been defined as the keratinocytes which can produce an array of immunoregulatory cytokines, the Langerhans cells as the major antigen presenting cells of the epidermis, the macrophages and dendritic cells as antigen presenting cell in the dermis, a special set of $\mathrm{T}$ cells with homing receptors for the skin, and endothelial cells expressing adhesion molecules thus enabling activated lymphocytes to move from the blood into the skin. The system is integrated in the draining lymph nodes to which the Langerhans cells migrate following contact with antigens in the skin. In response, antigen-specific $\mathrm{T}$ cells then proliferate and differentiate, and they move preferentially to the skin where they extravasate into areas of inflammation and are further stimulated by the cytokines produced locally by the keratinocytes.

As a result of UV radiation, a multistep process is induced ending with the down-regulation in immunity [reviewed in 2]. The first event must involve a chromophore or chromophores which absorb photons and then trigger the cascade. Even this initiating step is complex and there is evidence from various in vitro and in vivo sytems to implicate DNA damage ${ }^{3)}$, cis-urocanic acid (cis-UCA) ${ }^{4}$, cytoplasmic transcription factors ${ }^{5}$ and

\footnotetext{
${ }^{1}$ Department of Medical Microbiology, University of Edinburgh Medical School, Edinburgh, UK.

${ }^{2}$ National Institute of Public Health and Environment Protection, Bilthoven, The Netherlands.

Address for correspondence : Dr Mary Norval Department of Medical Microbiology, University of Edinburgh Medical School, Teviot Place, Edinburgh EH8 9AG, Scotland.
} 
membrane changes leading to clustering of cell surface receptors ${ }^{5}$. Mediators are generated locally and systemically, and multiple phenotypic and functional cellular changes occur. The number of epidermal Langerhans cells is reduced and their function as antigen presenting cells is depressed ${ }^{6}$. Dendritic cells soon accumulate in the draining lymph nodes ${ }^{7}$, followed by a migration of dendritic cells and macrophages to the irradiated cutaneous site ${ }^{8}$. The expression of adhesion and co-stimulatory molecules is changed, and there is frequently promotion of anti-inflammatory molecules with reduction in proinflammatory molecules [reviewed in 9]. Apoptosis is apparent. The inhibition of $\mathrm{T}$ cell responses to antigens encountered in the period immediately following the irradiation occurs with the generation of antigen-specific $T$ suppressor cells ${ }^{10}$. There is evidence for the promotion of $\mathrm{T}$ helper (Th) 2 associated cytokine production, such as interleukin-4 (IL-4) and IL-10, with a reduction in Thl associated cytokine production, such as interferon (IFN)- $\gamma$ and IL-2 [reviewed in 11]. However this dichotomy in cytokine production is not always clearcut, and the shift is likely to be controlled by several inter-related factors, prostaglandin $\mathrm{E}_{2}$ being one possibility.

Lifestyles have been modified somewhat in the past few years to reflect the fashion for tanning either by natural sunlight or by artificial lamps, frequent holidays in the sun, increased leisure time and the wearing of minimal clothing as soon as the sun shines. In addition there has been concern that the ozone layer in the stratosphere is being significantly depleted due to the emission of halogen-containing compounds. This leads to a concomitant increase in UV-B, thus augmenting the amount of biologically relevant radiation in sunlight reaching the surface of the Earth. Although environmental UV radiation is highly variable and difficult to measure adequately, systematic ozone depletion has been documented over many parts of the world: for example, increases in surface erythemal UV radiation relative to the values in the 1970 s are estimated as $7 \%$ and $4 \%$ at Northern Hemisphere mid-latitude in winter/spring and summer/autumn respectively, and $130 \%$ and $22 \%$ in the Antactica and Arctic respectively in spring ${ }^{12)}$. It is predicted that a maximum in ozone-depleting substances in the stratosphere will be reached around the time of the new millenium, then a slow recovery to pre-ozone depleted levels will occur over the next 50 years, although this could be compromised by non-compliance with the Montreal Protocol, increasing concentration of greenhouse gases, future volcanic eruptions and changing patterns of environmental pollution ${ }^{12}$.

Thus there is every possibility of longterm increased environmental UV exposure for a large proportion of human subjects globally. The consequences for the pathogenesis of infectious diseases require to be addressed. Using animal models, the minimal doses of $\mathrm{UV}$ required to modulate various aspects of immunity have been established. For down-regulation of delayed type hypersensitivity (DTH) which is an important response against virally-infected cells and certain microorganisms, as little as $100 \mathrm{~J} / \mathrm{m}^{2}$ UV-B is required in mice infected with herpes simplex virus (HSV) ${ }^{13)}$. For damage to Langerhans cells, $150-300 \mathrm{~J} / \mathrm{m}^{2} \mathrm{UV}-\mathrm{B}$ is needed as a minimum ${ }^{14}$, and to reach the photostationary state of isomerisation from trans to cis-UCA, about $1000 \mathrm{~J} / \mathrm{m}^{2}{ }^{23}$. One minimum erythemal dose (MED) for a person with skin type 1 who is fairskined, always burns and never tans, is about $200 \mathrm{~J} / \mathrm{m}^{2}$. Integrated solar UV radiation (erythemally weighted) in units of MED have been measured in various parts of the world including the UK. At approximately $50^{\circ} \mathrm{N}$ (south of England) the annual integrated solar UV radiation effective value is 1760 MEDs with about 400 MEDs per month in the summer ${ }^{15}$. Thus exposure to approximately 13 MEDs per day $\left(2600 \mathrm{~J} / \mathrm{m}^{2}\right)$ is possible in these months. On clear days around midday between latitudes $25^{\circ} \mathrm{N}$ and $25^{\circ} \mathrm{S}$, it is estimated that about 1-4 $\mathrm{J} / \mathrm{m}^{2}$ reaches ground level in one second ${ }^{16}$. Furthermore, the biologically effective irradiance of sunlight for inducing immunosuppression has been calculated, using information regarding solar exposure at different latitudes and an in vivo action spectrum in mice for the systemic suppression of contact hypersensitivity $(\mathrm{CH})^{17}$. It was shown, for example, that 50\% suppression would result if the animals were exposed for about 25 minutes to midday summer sunlight within the latitude $20^{\circ}$ to $40^{\circ} \mathrm{N}$ or $\mathrm{S}^{17}$. Therefore sunlight irradiation is biologically relevant to the effectiveness of the immune response and is likely to affect resistance to infectious agents in human subjects living in different parts of the world.

The following review summarises published information regarding UV-induced immunomodulation in, firstly, various animal models of infection and, secondly, in human populations. A risk assessment for this change is then estimated by extrapolating the animal data to humans. The final part includes speculation regarding the effects of $U V$ on persistent microbial infections, whether adaptation to exposure occurs, if the timing of the infection with respect to the UV irradiation is critical to the type of immune response generated, the repercussions for vaccination strategies, and suggested areas for future research.

\section{UV AND ANIMAL MODELS OF INFECTION}

In all instances, in recent years, mice or rats have been used which are frequently shaved prior to the irradiation and infection. The protocols have varied from one experimental model to another regarding UV dose and lamp, the type of microorganism, the route of inoculation and whether the infection occurs at a UV-exposed or non-exposed site, the timing of the infection with respect to UV exposure, and what parameter is being measured as an endpoint. The last has ranged from clinical symptoms, resistance to re-infection and counting the organisms in the irradiated animals to measurement of antigen- 
specific immune responses, most commonly DTH and in vitro lymphoproliferation. Therefore it is difficult to reach general conclusions but, in almost all cases, irradiation resulted in a suppression of resistance to the organism in question. Table 1 summarises published information in this area to date. It is particularly interesting to note that the UV can affect both skinassociated infections, such as HSV ${ }^{1921)}$, and others which are systemic with no skin involvement at any stage, such as rat cytomegalovirus ${ }^{23)}$, Listeria monocytogenes ${ }^{20)}$ and Trichinella spiralis ${ }^{35)}$. This implies that the changes induced by the irradiation, although initiated in the skin, can alter the type of immune response generated in sites other than the cutaneous environment through, perhaps, altered antigen presentation.

It is somewhat unrealistic to expect that all infections will be affected by UV similarly, given that the microorganisms themselves are so different, apart from the multifactorial nature of the immune responses they elicit in the host. There is interest currently in trying to define what determines whether a microorganism induces a predominantly Thl or Th2 response. This is likely to be complex depending on such factors as the antigen presenting cell population involved, the genetic background of the host, the extracellular or intracellular nature of the infectious agent and whether it causes an acute or a persistent infection ${ }^{37}$. The early production of $\mathrm{IL}-4$ is thought to stimulate a Th 2 response, while IL- 12 and IFN stimulate a Th1 response. Therefore if UV does promote a Th2 cytokine response whilst abrogating a Thl response, the immune response stimulated by organisms controlled mainly by Thl cytokines might be most affected by the exposure. Conversely the effects of UV might not be apparent in the case of Th2 responses being protective. In support of this hypothesis, Listeria monocytogenes and Borrelia burgdorferi, both of which elicit Th1 responses preferentially, showed suppressed immune responses following UV irradiation ${ }^{30,31}$, while, in the case of Schistosoma mansoni where the eggs stimulate a Th2 response which is also asociated with granuloma formation, no

Table 1. The effect of UV exposure on animal models of infection [18].

\begin{tabular}{|c|c|c|c|c|c|}
\hline Microorganism & Route of infection & Species & Timing of UV exposure & Antigen-specific effects of UVR & Reference \\
\hline \multirow[t]{3}{*}{ Herpes simplex virus } & Subcutaneous or epicutaneous & Mouse & Before infection & Lesions unaffected, suppressed DTH & [19] \\
\hline & Epicutaneous following immunisation & Mouse & Before challenge & $\begin{array}{l}\text { Lesions more severe, DTH unaffected, } \\
\text { decreased lymphoproliferation }\end{array}$ & {$[20]$} \\
\hline & Intradermal & Mouse & Before infection & $\begin{array}{l}\text { Lesions more severe, suppressed IFN- } \gamma \text {, } \\
\text { enhanced IL- } 4 \text { production }\end{array}$ & [21] \\
\hline Murine leukaemia virus & Intraperitoneal & Mouse & Before and after infection & $\begin{array}{l}\text { Decreased lymphoproliferation, greater } \\
\text { spleen histopathology, decreased MLR }\end{array}$ & [22] \\
\hline Reovirus & Intraperitoneal or intragastric & Mouse & Before infection & $\begin{array}{l}\text { Suppressed DTH, decreased lympho- } \\
\text { proliferation, decreased cytotoxic T cell } \\
\text { activity, clearance of virus unaffected }\end{array}$ & [23] \\
\hline Rat cytomegalovirus & Intraperitoneal & Rat & Before infection & $\begin{array}{l}\text { Decreased viral clearance, increased tissue } \\
\text { necrosis }\end{array}$ & [24] \\
\hline Mycobacterium bovis BCG & Subcutaneous & Mouse & Before or after infection & $\begin{array}{l}\text { Decreased clearance of bacteria and } \\
\text { enhanced dissemination, decreased } \\
\text { phagocytic function, suppressed } \\
\text { (temporary) depending on UV dose and site }\end{array}$ & {$[25-28]$} \\
\hline Mycobacterium lepraemurium & Subcutaneous & Mouse & Before infection & $\begin{array}{l}\text { Decreased clearance of bacteria, } \\
\text { increased local inflammatory response, } \\
\text { suppressed DTH (temporary) }\end{array}$ & [29] \\
\hline Listeria monocytogenes & Intravenous & Rat & Before infection & $\begin{array}{l}\text { Decreased clearance of bacteria, } \\
\text { decreased lymphoproliferation }\end{array}$ & {$[30]$} \\
\hline Borrelia burgdorferi & Subcutaneous (inactivated) & Mouse & Before immunisation & $\begin{array}{l}\text { Suppressed DTH, suppressed IgG2a and } 2 \mathrm{~b} \text {, } \\
\text { elevated IgG1 (after secondary challenge) }\end{array}$ & {$[31]$} \\
\hline \multirow[t]{2}{*}{ Candida albicans } & Subcutaneous (inactivated) & Mouse & Before or after immunisation & Suppressed DTH depending on UV dose & {$[27,32]$} \\
\hline & Intravenous following immunisation & Mouse & Before challenge & Decreased survival time & [33] \\
\hline Leishmania major & Intradermal & Mouse & Before and after infection & $\begin{array}{l}\text { Less severe skin lesions, no effect on } \\
\text { numbers of organisms, suppressed DTH, no } \\
\text { protection against re-infection }\end{array}$ & [34] \\
\hline Trichinella spiralis & Oral & Rat & After infection & $\begin{array}{l}\text { Decreased clearance of larvae, suppressed } \\
\text { DTH, suppressed lymphoproliferation }\end{array}$ & {$[35]$} \\
\hline Schistosoma mansoni & Percutaneous & Mouse & Before infection & $\begin{array}{l}\text { No effect on clearance, no effect on tissue } \\
\text { necrosis }\end{array}$ & {$[27,36]$} \\
\hline
\end{tabular}


such effect was found ${ }^{27,36)}$. It should be noted, however, that there is frequently not a clear distinction between the production of Th1 and Th 2 cytokines during an infection: furthermore preliminary evidence indicates that some Th2-associated cytokine responses may be down-regulated by UV exposure in particular animal models ( $\mathrm{H}$. van Loveren et al, submitted for publication).

\section{UV AND NATURAL HUMAN INFECTIONS}

For ethical reasons, it is obviously impossible to perform equivalent studies in human subjects as have been done in animals models, regarding possible effects of UV on infectious diseases. In addition epidemiological investigations which correlate incidence and severity of disease with personal sun exposure, season or latitude have not been undertaken as yet. However some limited information is available currently on human infections, including viral, bacterial and fungal examples, following natural exposure to sunlight or to an artificial UV source. Each microbial group will be considered in turn below. In most instances, changes in antigen-specific memory $\mathrm{T}$ cell responses have been tested, with clinical symptoms being examined in a few instances only. The interaction of UV and human infections has a long history as almost a hundred years ago Finsen demonstrated that "light" could be used successfully in the healing of skin tuberculosis (lupus vulgaris), although it had the opposite effect on smallpox lesions and on lung tuberculosis ${ }^{38}$.

There are three viruses of particular interest from the viewpoint of UV irradiation, namely HSV, human papillomavirus (HPV) and human immunodeficiency virus (HIV).

HSV type 1 typically causes vesicular "cold sores" in the orofacial region of the body and type 2 in the genital region. Following the primary infection, latency is established in the ganglia for life, and the virus can reactivate at intervals, appear in the skin again and replicate to form recrudescent lesions at the same site as the initial lesions. Sudden exposure to UV on this site is one common triggering factor for recrudescence: in one study in Edinburgh about $30 \%$ of people who suffered from recrudescent orofacial HSV infections recognised sunlight as a stimulus. This has also been shown experimentally now in three studies of HSV type $1^{39-41)}$ and one of HSV type $2^{42)}$ where subjects were exposed to burning doses of UV locally, and recurrence of their HSV occurred. It is not known exactly what happens here as the virus has to reactivate first in the ganglia, perhaps due to the transactivation of regulatory UV-responsive elements, and then replicates in the periphery. The second event may be controlled primarily by the host immune response, and there is evidence that the UV exposure may suppress this sufficiently to allow the cytopathic effects of the virus to become apparent. While there may be local immunosuppression, most probably due to altered antigen pre- sentation in the skin ${ }^{43}$, UV-induced down-regulation of systemic HSV T cell immunity is more controversial. Using in vitro lymphoproliferation in response to HSV as a measure of T cell activity, UV exposure as experienced by subjects undergoing UV-B phototherapy for psoriasis did not cause any alteration ${ }^{43}$ 44). In addition HSV-specific cytotoxic T cell activity was not changed during the phototherapy ${ }^{45}$. In contrast, another study reported a reduction in lymphoproliferative activity to HSV following a single whole-body exposure to one MED ${ }^{46)}$.

There are over $100 \mathrm{HPV}$ types, some associated with the development of squamous cell carcinomas in immunosuppressed individuals, of whom the renal allograft recipients have been most studied ${ }^{47}$, and in subjects with the rare genetic disease epidermodysplasia verruciformis who have an underlying defect in cell-mediated immunity ${ }^{48}$. In both groups, the tumours develop almost totally on areas of the body exposed naturally to sunlight, especially the face and the backs of the hand. The prevalence is highest in sunny climates. The exact roles of UV and HPV have not been defined and are likely to be complex. It is known that HPV infections are frequently protracted, with some evidence for local immunomodulation in the lesion itself ${ }^{49}$. Exposure to the sun could induce damage to DNA in the epidermis with perpetuation and amplification of this change due to the abnormal proliferation of HPV-infected cells. Furthermore immune responses in the local site could be down-regulated by the UV which may be of significance even in subjects who are already considerably suppressed by taking drugs or genetically. In practical terms, immunosuppressed individuals should be advised to avoid sun exposure.

The situation regarding the third virus, HIV, is also unclear at the present time. The skin is involved as a major organ in HIV infections ${ }^{50)}$. Indeed more that $90 \%$ of patients develop disorders of the skin or mucous membranes which can occur at any stage of the disease, not only during the terminal deficiency. There are at least three reasons for considering that UV could potentially influence the progression of the disease. In the first place, exposure to UV has been shown to activate HIV in several transgenic mouse models and in vitro by damage to DNA and alteration in cellular transcription factors ${ }^{51)}$. Secondly, there is a prolonged interval of several years after viral infection and before the development of acquired immunodeficiency syndrome, and transcriptional activation of the structural genes of the virus is thought to be important in controlling this process. Thirdly, as the disease progresses, there may be a shift from a Th1 to a Th2 profile of cytokine production ${ }^{52}$, a change which is thought to be enhanced by UV. However, thus far, there is no evidence to substantiate a role for solar UV exposure in the exacerbation of HIV infections and, indeed, in one recent study, a protective effect was noted ${ }^{53}$.

Regarding bacteria, T cells mediating DTH and cytotoxicity, 
together with macrophage activation, represent the major protective immune responses against intracellular bacteria. Two studies have monitored UV-induced modulation in local memory responses to such organisms, namely $M$. leprae and $M$. tuberculosis. In the first, Cestari et al. ${ }^{54)}$ irradiated healthy contacts of leprosy patients who were lepromin-positive and tested their antigen-specific responses by injecting lepromin (a heatkilled suspension of $M$. leprae) into the irradiated site. The size of the lepromin-induced granuloma, characterised by tissue necrosis and fibrosis, was reduced in the irradiated site, together with a lower number of infiltrating CD4-positive cells. It is interesting to note in this context that an increased incidence of leprosy lesions has been reported to occur in areas of the body exposed to sunlight ${ }^{55}$. In the second, Damian et al. ${ }^{56)}$ irradiated subjects who had previously been vaccinated with Bacillus Calmette-Guerin (BCG) and were Mantoux-positive. Their mycobacterial DTH responses were then tested in exposed and unexposed sites. It was found that suppression of DTH occurred in the irradiated site, but not in the distant unirradiated site. Interestingly a suberythemal UV dose (each day for 5 days) was sufficient to induce this effect. However when tested after chronic UV exposure (daily for 4-5 weeks), the suppression was not significant, indicating, perhaps, that adaptive mechanisms may be generated to counteract the UV effects (see final section below).

Few investigations have focussed on UV and fungal infections. O'Dell et al ${ }^{57}$ tested the DTH response to $C$. albicans by intradermal injection into sun-damaged skin in the neck of volunteers. The response was suppressed compared with that elicited in normal back skin in the same individual. C. albicans was also included as one of several antigens in a study to test whether chronic solar-simulated irradiation suppressed DTH, either locally or systemically ${ }^{58}$. The other antigens were tetanus toxin, diphtheria toxin, Streptococcus antigen, tuberculin, Trichophyton and Proteus antigen, prepared as a standard Multitest kit. It was reported that, following 10 incremental UV doses, the overall DTH score on challenge was reduced by $60-70 \%$, both at the exposed and an unexposed site, compared with the response in the same individual before irradiation.

Therefore, although the human studies are sparse and rely mainly on DTH as an indicator of immunity, yet they do indicate a general microbial-specific down-regulation following UV exposure. As DTH is a memory response, this implies that UV is capable of modifying an already established immune mechanism. The outcome of the change in terms of resistance to re-infection or reactivation of persistent human pathogens is unknown at present.

\section{ASSESSMENT OF RISK OF UV RADIATION TO MICROBIAL IMMUNITY}

In view of the difficulty of obtaining experimental data regarding UV exposure and its effect on human infections, and the lack of epidemiological information, it may be possible to use the immunological results obtained in the animal models of infection and to extrapolate from these to the human situation ${ }^{59)}$. A start has been made to this so-called "parallelogram" approach ${ }^{60,61)}$. A UV dose response was constructed for the suppression of $T$ cell lymphoproliferation in rats infected intravenously with $L$. monocytogenes ${ }^{30}$. It was found that $6800 \mathrm{~J} / \mathrm{m}^{2}$ inhibited the response by $50 \%$ and the same dose also inhibited the clearance of bacteria from the spleen. For example, at 4 days post-infection there was about 8 -fold more bacteria in the spleen of the irradiated rats than in the control animals. A comparison of human and rat skin to the suppressive effects of UV-B exposure, as assessed by the mixed skin lymphocyte reaction, revealed that rats were about 3.85 times more sensitive than humans ${ }^{60}$. This figure was taken as a measure of inter-species variation. In addition a figure of 0.5 was added to account for possible differences between individuals in their susceptibility to UV-induced immunosuppression (intra-species variation). Thus the estimated UV-B dose required to suppress $\mathrm{T}$ cell immunity to Listeria by $50 \%$ in human subjects was $6800 \times 3.85 \times 0.5=13100 \mathrm{~J} / \mathrm{m}^{2}$. It was then possible to extrapolate this calculation to solar exposure using an action spectrum for suppression of $\mathrm{CH}$ in mice and the biological effective irradiance at certain latitudes ${ }^{17}$. Thus, for example, it was predicted that exposure for about $100 \mathrm{~min}$ utes at $40^{\circ} \mathrm{N}$ (Spain, Italy, Japan) around noon in July on a clear day would suppress cellular immunity to Listeria by $50 \%{ }^{61)}$. A 5\% decrease in the ozone layer would shorten this exposure time by approximately $2.5 \%$. Similar calculations can be performed using the absorption spectrum for UCA ${ }^{62}$, the action spectrum for DNA damage ${ }^{63)}$ and the action spectrum for the suppression of the mixed skin lymphocyte reaction ${ }^{64)}$. These results are shown in Figure 1.

Several studies have examined the suppression in hypersensitivity responses to simple chemicals in human subjects due to UV exposure and have found that the effective dose is about the same order as the theoretical assessments above ${ }^{8,65,66)}$. The most recent of these used a single dose of solar simulated radiation and showed that suppression of $\mathrm{CH}$ occurred, both locally and systemically, after exposure to 3 MEDs ${ }^{66}$ ). Such a dose would be achievable in the UK with one hour of summer sunlight around noon on a clear day. These findings validate the parallelogram approach as a means of estimating human susceptibility to UV radiation. 


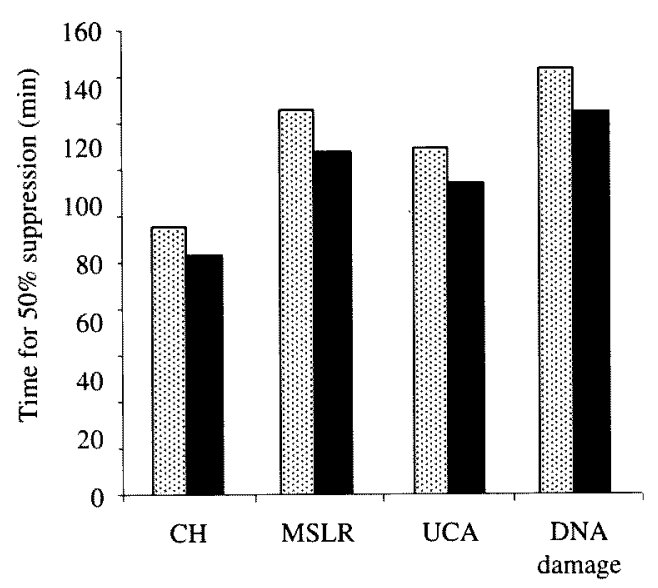

Figure 1. The solar exposure time necessary for $50 \%$ suppression of cellular immunity in human subjects as extrapolated from a rat model (Listeria infection) following $0 \%$ (dotted bars) or $20 \%$ (solid bars) depletion in ozone at 40 degrees north, clear sky, around noon. Calculations are based on 4 action spectra: suppression of contact hypersensitivity $(\mathrm{CH}){ }^{17}$, suppression of mixed skin lymphocyte reaction (MSLR) ${ }^{64)}$, urocanic acid absorption spectrum (UCA) ${ }^{621}$ and the spectrum for the accumulation of DNA photoproducts (DNA damage) ${ }^{63)}$.

\section{CONCLUSIONS AND UNANSWERED QUESTIONS}

The account above demonstrates that the present knowledge concerning UV and the resistance to infectious diseases is undoubtedly patchy, especially with regard to human infections. However it cannot be disputed that exposure has the potential to suppress at least some microbial immune responses and that this risk will increase as ozone depletion occurs. Whether the immunomodulation alters the course of the disease is the most critical question. Immune responses are complex and inter-dependent so that, if one is down-regulated, another may compensate. Certainly with regard to HSV infection, sunlight can act as the stimulus for recrudescence. It would be interesting to examine the situation with some of the other human herpesviruses which also cause persistent infections, such as Epstein Barr virus and cytomegalovirus. In addition an effective immune response is particularly important in the control of oncogenesis and, as at least $15 \%$ of human tumours are now known to have a viral involvement, it will be very important to examine the potential effects of UV in these situations.

Questions arise regarding vaccination policies and whether it might be inadvisable to immunise an individual who showed evidence of recent, exceptional sun exposure. In this case the $T$ cell response generated may not be protective and, if the data from animal models hold true for humans, the suppressed state is long-lasting, once established ${ }^{67}$. A study using hepatitis B virus subunit vaccine in recently irradiated and unirradiated persons is underway currently in the Netherlands at the National Institute of Public Health and the Environment in
Bilthoven , in collaboration with the University of Utrecht, which is designed to address these issues.

In most of the animal models to date, the UV exposure precedes the microbial infection. Therefore the modulation assessed is in the primary immune response. In the natural situation, this sequence of events may be rather infrequent and it may be more relevant to study models where the immune response has already been generated before the UV. In this case, the detailed mechanism by which UV may act is unknown and requires urgent investigation. Certainly in the few studies in which memory responses have been examined in human subjects, there was UV-induced suppression of DTH at least ${ }^{54,56,58)}$, but no information regarding susceptibility to reinfection is available as yet.

A further uncertainty concerns possible adaptation to the immunosuppressive effects of UV. In many experimental protocols to date, a single dose or perhaps up to five UV doses given daily are used before inoculation of the infectious agent. Under natural circumstances where we are exposed to sunlight on a more or less daily basis, would there still be the same chance of generating suppressed immunity? Two studies involving infections conclude that adaptive mechanisms may, indeed, provide protection. Damian et al. ${ }^{56)}$ reported that the Mantoux reaction in human subjects failed to be suppressed after prolonged UV exposure (4-5 weeks). Jeevan et al. ${ }^{29}$ ) found that suppressed DTH responses to $M$. leprae were not maintained in mice that were chronically irradiated (longer than 3 months).

A further gap in our knowledge concerns the whole area of epidemiology and clinical disease. Figures are required to 
indicate whether, for example, infectious diseases are more common and/or more severe in people who have enjoyed recent sunshine holidays. Latitude studies with regard to the incidence of infections would also be appropriate. Ozone depletion requires consideration in this context. Rather than relying on memory, it is desirable to use personal dosimeters to evalute UV exposure accurately in any future surveys.

The final area which merits attention is that of genetic susceptibility and resistance to the immunosuppressive effects of UV radiation. There is evidence that some degree of genetic control exists in both mice and human subjects. In mice, strains can be separated on the basis of susceptibility/resistance to UV-induced suppression of $\mathrm{CH}$, and these genes are not the same for local and systemic responses ${ }^{65,68)}$. Similarly people can be divided into the two groups on the basis of local suppression of $\mathrm{CH}^{8,69}$ which is largely independent of skin pigmentation ${ }^{70}$. However other do not find such a distinction ${ }^{66,71)}$ and differences in lamps, doses and sensitisers may be important. It would be interesting to investigate DTH to microbial antigens rather than $\mathrm{CH}$ in both humans and mice as this immune response is more relevant to the control of infection. The added complication of such studies is that there is frequently genetic susceptibility of the host to particular infecting microorganisms which would have to be considered separately from the UV genetics.

\section{ACKNOWLEDGEMENT}

Work in the authors' laboratories is funded by a grant from the EC Environment Programme (ENU4-CT96-0192).

\section{REFERENCES}

1. Kripke ML, Fisher MS. Immunologic parameters of ultraviolet carcinogenesis. J Natl Cancer Inst, 1976; 57: 211-215.

2. Beissert S, Granstein RD. Physiology and pathology of skin photoimmunology. In; Bos JD, ed. Skin Immune System (SIS), 2nd ed. CRC Press, New York, 1997; 399416.

3. Vink AA, Yarosh DB, Kripke ML. Chromphore for UVinduced immunosuppression: DNA. Photochem Photobiol, 1996; 63: 383-386.

4. Norval M. Chromphore for UV-induced immunosuppression: urocanic acid. Photochem Photobiol, 1996; 63: 386-390.

5. Schwarz T. UV light affects cell membrane and cytoplasmic targets. J Photochem Photobiol B: Biol, 1998; 44: 91-96.

6. Toews GB, Bergstresser PR, Streilein JW. Epidermal Langerhans cells density determines whether contact hypersensitivity or unresponsiveness follows skin paint- ing with DNFB. J Immunol, 1980; 124: 445-453.

7. Moodycliffe AM, Kimber I, Norval M. The effects of ultraviolet B irradiation and urocanic acid isomers on dendritic cell migration. Immunology, 1992; 77: 394399.

8. Cooper KD, Oberhelman L, Hamilton TA, et al. UV exposure reduces immunization rates and promotes tolerance to epicutaneous antigens in humans: relationship to dose, CD1a:DR ${ }^{+}$epidermal macrophage induction, and Langerhans cell depletion. Proc Natl Acad Sci USA, 1992; 89: 8497-8501.

9. Krutmann J. Therapeutic photoimmunology: photoimmunological mechanisms in photo(chemo)therapy. J Photochem Photobiol B: Biol, 1998; 44: 159-164.

10. Fisher MS, Kripke ML. Suppressor T lymphocytes control the development of primary skin cancers in ultraviolet-irradiated mice. Science, 1982; 216: 1133-1134.

11. Ullrich SE. Does exposure to UV radiation induce a shift to a Th-2-like immune reaction? Photochem Photobiol, 1996; 66: 254-258.

12. Madronich S, McKenzie RL, Bjorn LO, Caldwell MM. Changes in biologically active ultraviolet radiation reaching the Earth's surface. J Photochem Photobiol B: Biol, 1998; 46: 5-19.

13. El-Ghorr AA, Norval M. The UV waveband dependencies in mice differ for the suppression of contact hypersensitivity, delayed hypersensitivity and cis-urocanic acid formation. J Invest Dermatol, 1999 ; 112: 757-762.

14. Aberer W, Schuler G, Stingl G, Honigsmann H, Wolff K. Ultraviolet light depletes surface markers of Langerhans cells. J Invest Dermatol, 1981; 76: 202-210.

15. National Radiological Protection Board Report, Chilton, UK. Effects of ultraviolet radiation on human health and health effects from ultraviolet radiation, 1995; 6: 15-21.

16. Frederick JE. In; Titus JG, ed. Effects of Changes in Stratospheric Ozone and Global Climate, US Environmental Protection Agency, 1986; Vol 1: 202-210.

17. De Fabo EC, Noonan FP, Frederick JE. Biologically effective doses of sunlight for immune suppression at various latitudes and their relationship to changes in stratospheric ozone. Photochem Photobiol, 1990; 52: 811-817.

18. Halliday KE, Norval $M$. The effect of ultraviolet radiation on infectious diseases. Rev Med Microbiol, 1997; 8: 179-188.

19. Norval M, El-Ghorr AA. UV and mouse models of herpes simplex virus infection. Photochem Photobiol, 1996; 64: 242-245.

20. El-Ghorr AA, Norval M. The effect of UV-B irradiation on secondary epidermal infection of mice with herpes simplex virus type 1. J Gen Virol, 1996; 77: 485-491.

21. Yasumoto S, Moroi Y, Koga T, et al. Ultraviolet-B irradiation alters cytokine production by immune lympho- 
cytes in herpes simplex virus-infected mice. J Dermatol Sci, 1994; 8: 218-223.

22. Brozek CM, Shopp GM, Ryan SL, et al. In vivo exposure to ultraviolet radiation enhances pathogenic effects of murine leukemia virus, LP-BM5, in murine acquired immunodeficiency syndrome. Photochem Photobiol, 1992; 56: 287-295.

23. Letvin NL, Kauffman RS, Finberg R. T lymphocyte immunity to reovirus: cellular requirements for generation and role in clearance of primary infections. J Immunol, 1981; 127: 2334-2339.

24. Garssen J, Van Der Vliet H, De Klenk A, et al. A rat cytomegalovirus infection model as a tool for immunotoxicity testing. Eur J Pharmacol Environ Toxicol Pharmacol Sect, 1995; 292: 223-231.

25. Jeevan A, Kripke ML. Effect of a single exposure to ultraviolet radiation on Mycobcterium bovis Bacillus Calmette-Guerin infection in mice. J Immunol, 1989; 143: 2837-2843.

26. Jeevan A, Kripke ML. Alteration of the immune response to Mycobacterium bovis BCG in mice exposed chronically to low doses of UV radiation. Cell Immunol, 1990; 130: 32-41.

27. Jeevan A, Evans R, Brown EL, Kripke ML. Effect of local ultraviolet irradiation on infections of mice with Candida albicans, Mycobacterium bovis BCG, and Schistoma mansoni. J Invest Dermatol, 1992; 99: 59-64.

28. Jeevan A, Ullrich SE, De Gracia M, Shah R, Sun Y. Mechanism of UVB-induced suppression of the immune response to Mycobacterium bovis Bacillus CalmetteGuerin: role of cytokines on macrophage function. Photochem Photobiol, 1996; 64: 259-266.

29. Jeevan A, Gilliam K, Heard H, Kripke ML. Effects of ultraviolet radiation on the pathogenesis of Mycobacterium lepraemurium infection in mice. Exp Dermatol, 1992; 1: 152-160.

30. Goettsch W, Garssen J, De Klerk A et al. Effects of ultraviolet-B exposure on the resistance to Listeria monocytogenesis in the rat. Photochem Photobiol, 1996; 63: 672679.

31. Brown EL, Rivas JM, Ullrich SE, et al. Modulation of immunity to Borrelia burgdorferi by ultraviolet irradiation. Eur J Immunol, 1995; 25: 3017-3022.

32. Denkins Y, Fidler IJ, Kripke ML. Exposure of mice to UV-B radiation suppresses delayed hypersensitivity to Candida albicans. Photochem Photobiol, 1989; 49: 615619.

33. Denkins YM, Kripke ML. Effects of UV irradiation on lethal infection of mice with Candida albicans. Photochem Photobiol, 1993; 57: 266-271.

34. Giannini SH. Effects of ultraviolet B irradiation on cutaneous Leishmaniasis. Parasitol Today, 1992; 8: 44-48.
35. Goettsch W, Garssen J, De Gruijl FR, Van Loveren H. UVB-induced decreased resistance to Trichinella spirilis in the rat is related to impaired cellular immunity. Photochem Photobiol, 1996; 64: 581-585.

36. Noonan FP, Lewis FA. UVB-induced immune suppression and infection with Schistosoma mansoni. Photochem Photobiol, 1995; 61: 99-105.

37. Romagnani S. Understanding the role of Th1/Th2 cells in infection. Trends Microbiol, 1996; 4: 470-473.

38. Finsen NR. Phototherapy. Sequira JH, transl, Edward Arnold, London, 1901, p 79.

39. Spruance SL. Pathogenesis of herpes simplex labialis: experimental induction of lesions with UV light. J Clin Microbiol, 1985; 22: 366-368.

40. Perna JJ, Mannix ML, Rooney JF, Notkins AL, Straus SE. Reactivation of latent herpes simplex virus infection by ultraviolet light: a human model. J Am Acad Dermatol, 1987; 17: 473-478.

41. Rooney JF, Bryson Y, Mannix ML, et al. Prevention of ultraviolet-light-induced herpes labialis by sunscreen. Lancet, 1991; 338: 1419-1422.

42. Klein KL, Linnemann CC. Induction of recurrent genital herpes simplex virus type 2 infections by ultraviolet light. Lancet, 1986; i: 796-797.

43. Gilmour JW, Vestey JP, Norval M. The effect of UV therapy on immune function in patients with psoriasis. $\mathrm{Br}$ J Dermatol, 1993; 129: 28-38.

44. Guckian M, Jones CD, Cooper J, et al. Immunomodulation at the initiation of phototherapy and photochemotherapy of psoriasis. Photodermatol Photoimmunol Photomed, 1995; 11: 163-169.

45. Neill WA, Halliday KE, Norval M. Differential effect of phototherapy on the activities of huamn natural killer cells and cytotoxic T cells. J Photochem Photobiol B: Biol, 1998 ; 47: 129-135.

46. Miura S, Kulka M, Smith CC, et al. Cutaneous ultraviolet radiation inhibits herpes simplex virus-induced lymphoproliferation in latently infected subjects. Clin Immunol Immunopathol, 1994; 72: 62-69.

47. Proby C, Storey A, McGregor J, Leigh I. Does human papillomavirus infection play a role in non-melanoma skin cancer? Papillomavirus Report, 1996; 7: 53-60.

48. Majewski S, Jablonska S. Epidermodysplasia verruciformis as a model of human papillomavirus-induced genetic cance of the skin. Arch Dermatol, 1995; 131: 1312-1318.

49. Jackson M, Benton EC, Hunter JAA, Norval M. Local immune responses in cutaneous warts: an immunocytochemical study of Langerhans' cells, $\mathrm{T}$ cells and adhesion molecules. Europ J Dermatol, 1994; 4: 399-404.

50. Henry M, Tschachler E. The skin immune system in the course of HIV-1 infection. Photochem Photobiol, 1996; 
64: 275-279.

51. Zmudzka BZ, Miller SA, Jacobs ME, Beer JB. Medical UV exposures and HIV activation. Photochem Photobiol, 1996; 64: 246-253.

52. Clerici M, Shearer GM. A Th1-Th2 switch is a critical step in the etiology of HIV infection. Immunol Today, 1993; 14: 107-111.

53. Saah AJ, Horn TD, Hoover DR, et al. Solar ultraviolet radiation exposure does not appear to exacerbate HIV infection in homosexual men. AIDS, 1997; 11: 17731778.

54. Cestari TF, Kripke ML, Baptists PL, Bakos L, Bucana CD. Ultraviolet radiation decreases the granulomatous response to lepromin in humans. J Invest Dermatol, 1995; 105: 8-13.

55. Patki AH. Hypothesis: solar ultraviolet radiation and the initial skin lesions of leprosy. Int J Leprosy, 1991; 59: 492-493.

56. Damian DL, Halliday GM, Taylor CA, Barnetson R StC. Ultraviolet radiation induced suppression of Mantoux reactions in humans. J Invest Dermatol, 1998; 110: 824827.

57. O'Dell BL, Jessen T, Becker LE, Jackson RT, Smith EB. Diminished immune response in sun-damaged skin. Arch Dermatol, 1980; 116: 559-561.

58. Moyal D, Courbiere C, Le Corre Y, de Lacharriere O, Hourseau C. Immunosuppression induced by chronic solar-simulated irradiation in humans and its prevention by sunscreens. Eur J Dermatol, 1997; 7: 223-225.

59. Selgrade MJK, Cooper KD, Devlin RB, Van Loveren H, Biagini RE, Luster MI. Immunotoxicity: bridging the gap between animal research and human health effects. Fund Appl Toxicol, 1995; 24: 13-21.

60. Garssen J, Goettsch W, De Gruijl F, Slob W, Van Loveren $\mathrm{H}$. Risk assesment of UVB effects on resistance to infectious diseases. Photochem Photobiol, 1996; 64: 269-274.

61. Garssen J, Norval M, El-Ghorr A, et al. Estimation of the effect of UVB exposure on the human immune system and related resistance to infectious diseases and tumours. J Photochem Photobiol B: Biol, 1998; 42: 167-179.

62. De Fabo EC, Noonan FP. Mechanism of immunosuppression by ultraviolet irradiation in vivo. I. Evidence for the existence of a unique photoreceptor in skin and its role in photoimmunology. J Exp Med, 1983; 158: 84-98.

63. Matsunaga $T$, Hieda $K$, Nikaido $O$. Wavelength dependent formation of thymine dimers and (6-4) photoproducts in DNA by monochromatic ultraviolet light ranging from 150 to $365 \mathrm{~nm}$. Photochem Photobiol, 1991; 54: 403-410.

64. Hurks HMH, Out-Luiting C, Vermeer BJ, Claas FHJ, Mommaas AM. The action spectra for UV-induced suppression of MLR and MECLR show that immuosuppression is mediated by DNA damage. Photochem Photobiol, 1995; 62: 449-453.

65. Yoshikawa T, Streilein JW. Genetic basis of the effects of ultraviolet light B on cutaneous immunity. Evidence that polymorphism at the Tnfa and LPS loci governs susceptibility. Immunogenetics, 1990; 32: 398-405.

66. Kelly DA, Walker SL, McGregor JM, Young AR. A single exposure of solar simulated radiation suppresses contact hypersensitivity responses both locally and systemically in humans: quantitative studies with high-frequency sound. J Photochem Photobiol B: Biol, 1998; 44: 130142.

67. Howie SE, Norval M, Maingay J, Ross JA. Two phenotypically distinct $\mathrm{T}$ cells $\left(\mathrm{Ly} \mathrm{1}^{+} 2^{-}\right.$and $\left.\mathrm{Ly} \mathrm{l}^{-2} 2^{+}\right)$are involved in ultraviolet-B-light induced suppression of the efferent DTH response to HSV-1 in vivo. Immunology, 1986; 58: 653-658.

68. Noonan FP, Hoffman HA. Susceptibility to immunosuppression by ultraviolet $B$ radiation in the mouse. Immunogenetics, 1994; 39: 29-39.

69. Yoshikawa T, Rae V, Bruins-Slot W, et al. Susceptibility to effects of UVB radiation on induction of contct hypersensitivity as a risk factor for skin cancer in humans. J Invest Dermatol, 1990; 95: 530-536.

70. Schreiber A, Hollis DE, Murray E, McCarthy WH, Milton GW. Effects of exposure to ultraviolet light on epidermal Langerhans cells and melanocytes in Australians of Aboriginal, Asian and Celtic descent. Photodermatology, 1987; 3: 15-25.

71. Yamawaki M, Hatiyar SK, Anderson CY, et al. Genetic variation in low-dose UV-induced suppression of contact hypersensitivity and in skin photocarcinogenesis. J Invest Dermatol, 1997; 109: 716-721. 